\title{
Adapting the short form of the Coping Inventory for Stressful Situations into Chinese
}

\author{
This article was published in the following Dove Press journal: \\ Neuropsychiatric Disease and Treatment \\ 27 June 2017 \\ Number of times this article has been viewed
}

\section{Chun $\mathrm{Li}^{\prime}$ \\ Qing Liu ${ }^{2}$ \\ $\mathrm{Ti} \mathrm{Hu}{ }^{3}$ \\ Xiaoyan Jin'}

'International School of Chinese Studies, Northeast Normal University, Changchun, ${ }^{2}$ Department of Nuclear Medicine and Medical PET Center, The Second Hospital of Zhejiang University School of Medicine,

Zhejiang University, Hangzhou, ${ }^{3}$ School of Physical Education and Sports, Beijing Normal University, Beijing, People's Republic of China
Correspondence: Qing Liu Department of Nuclear Medicine and Medical PET Center, The Second Hospital of Zhejiang University School of Medicine, Zhejiang University, No 88 Jiefang Road, Hangzhou 310009, People's Republic of China

$\mathrm{Tel}+8657187767188$

Email lq1988I22I@I26.com

$\mathrm{Ti} \mathrm{Hu}$

School of Physical Education and

Sports, Beijing Normal University,

19 Xinjiekouwai Avenus, Beijing 100875,

People's Republic of China

Tel +86105880 8038

Email huti777@।26.com
Objectives: The Coping Inventory for Stressful Situations (CISS) is a measurement tool for evaluating stress that has good psychometric properties. We investigated the applicability of a short-form version of the CISS in a large sample of Chinese university students.

Methods: Nine hundred and seventy-two Chinese university students aged 18-30 years ( mean $=20.15$, standard deviation $=3.26$ ) were chosen as subjects, of whom 101 were randomly selected to be retested after a 2-week interval.

Results: The results of a confirmatory factor analysis revealed that the root mean square error of approximation of a four-factor model was 0.06 , while the comparative fit index was 0.91 , the incremental fit index was 0.93 , the non-normed fit index was 0.91 , and the root mean residual was 0.07. The Cronbach's $\alpha$ coefficients for the task-oriented, emotion-oriented, distraction, and social diversion coping subscales were $0.81,0.74,0.7$, and 0.66 , respectively. The 2 -week test-retest reliability was $0.78,0.74,0.7$, and 0.65 for the task-oriented, emotion-oriented, distraction, and social diversion coping subscales, respectively. In the Chinese version of the CISS short form, task-oriented coping was positively correlated with positive affect and extraversion and negatively correlated with neuroticism; emotion-oriented coping was negatively correlated with extraversion and positively correlated with negative affect, anxiety, and neuroticism; distraction coping was positively correlated with neuroticism, extroversion, anxiety, positive affect, and negative affect and negatively correlated with psychoticism; and social diversion coping was positively correlated with extroversion and positive affect and negatively correlated with psychoticism.

Conclusion: The Chinese version of the CISS short form is satisfactorily valid and reliable among Chinese university students.

Keywords: stress, coping, factor analysis, reliability, validity, Chinese university students

\section{Introduction}

Stress and coping are difficult to disentangle. The concepts of coping were different across studies. Lyon ${ }^{1}$ thought coping was an effort to manage threat or stress emotion. $\mathrm{Keil}^{2}$ thought one had to confront events either external or internal with varying degrees of success to cope, while Khosla ${ }^{3}$ held a view that coping as process of managing internal and external needs that were exceeding a person's resources. We chose the original concept of Lazarus and Folkman. Coping is defined as "continually changing [one's] behavior and cognition to cope with extra needs which [are] beyond [one's] competence."4 Coping is a major factor influencing individuals' emotional and behavioral reactivity to stress. How people can successfully cope with stress situations and the relations between different coping strategies and body-mind health have consistently attracted researchers' attention. ${ }^{5}$

Research on coping has generally shown that coping behavior is multidimensional. ${ }^{6}$ Endler and Parker ${ }^{7,8}$ presented an exceedingly simple way of conceptualizing coping 
strategies by dividing them into task-oriented coping, emotion-oriented coping, and avoidance-oriented coping, which they in turn used to establish the Coping Inventory for Stressful Situations (CISS). This scale comprises 48 items and has, since its development, become one of the most extensively used tools with good psychometric properties. ${ }^{9-11}$ Task-oriented coping refers to the use of problem-solving and information seeking to change stressful situations; emotionoriented coping is defined as attempts to reduce stress through emotional reactions (eg, self-blame, depression, and anger) or rumination; and avoidance-oriented coping refers to the use of distraction, diversion, and withdraw behaviors to avoid stress. Avoidance-oriented coping can be further divided into two sub-dimensions called distraction coping and social diversion coping. The CISS short form, ${ }^{12}$ which comprises 21 items, was designed according to these four dimensions (task-oriented, emotion-oriented, distraction, and social diversion copings). However, so far, the psychometric properties of a Chinese version have not been established.

Coping style is closely connected with body-mind health. In general, task-oriented coping is related to greater happiness, while emotion- and avoidance-oriented copings are usually related to unhealthy psychological phenomena. ${ }^{13,14}$ For instance, decreases in depression symptoms were related to less use of emotion-oriented coping and greater use of taskoriented coping, while a relapse in depression was related to the use of avoidance-oriented coping. ${ }^{13}$ Investigations of the relationship between personality traits and coping have shown that task-oriented coping relates to conscientiousness. In contrast, emotion-oriented and avoidance-oriented copings relate to undesirable personality traits such as neuroticism. ${ }^{15}$ Research on patients with major depressive disorder has similarly demonstrated that task-oriented and avoidance-oriented copings are related to extraversion and emotion-oriented coping. ${ }^{16}$ Therefore, individual coping styles have been shown to relate to personality traits in both healthy persons and patient groups.

Overall, the purpose of this study is to investigate the psychometric properties of the Chinese version of the CISS, which contains 21 items (Coping Inventory for Stressful Situations - Short Form for Chinese [CISS-SFC]/CISS-21), and to determine the criterion validity by examining the scale's relationship with anxiety, depression, positive affect, negative affect, and personality traits. Based on the previous studies of the CISS-21, ${ }^{17}$ we hypothesized that, like the original version of the CISS-21, the Chinese version would have a four-factor structure. We also assumed that there would be connections between coping styles and personality traits, anxiety, depression, positive affect, and negative affect.

\section{Methods \\ Participants}

Students from universities in the southwest, northwest, southeast, and northeast of China were selected as participants. Specifically, we randomly chose two public psychology classes from Guangxi University, Northwest Normal University, Southeast University, and Liaoning Normal University. We collected 1,000 questionnaires in total, of which 972 were valid. The questionnaires were obtained from 234 male students and 738 female students; together, their mean age was 20.15 years. We randomly chose 101 to take part in a retest after 2 weeks to confirm the test-retest reliability of the questionnaire. All participants provided written informed consent before participating in the experiment.

\section{Measures \\ CISS-SFC}

The CISS-SFC measures three dimensions of coping - taskoriented coping, emotion-oriented coping, and avoidanceoriented coping - and comprises 21 items in total. The CISS-SFC was based on the original CISS, which had 48 items. ${ }^{18}$ The participants rate each item on a five-point Likert scale (1= "not at all" to 5= "very much") to determine which coping strategies they use for different stressful situations. Task-oriented coping here was defined as making an effort to purposefully resolve the stressful situation (eg, thinking about solutions for similar stressful situations and engaging in corrective action). Emotion-oriented coping was defined as focusing on decreasing feelings of stress and concentrating on one's own feelings (eg, self-blame, feeling upset, or hoping for the improvement of the things themselves). Avoidance-oriented coping refers to behaviors, such as distraction (eg, buying something) or social diversion (such as visiting friends), that aim to avoid having to deal with stressful situations.

The stem question requests that individuals rate how much they engage in each activity when they encounter a difficult, stressful, or upsetting situation. For the current investigation, the CISS was translated from English to Chinese and back-translated by a specialist to ensure comprehensibility and comparability with the original form. The CISS, as noted earlier, divides avoidance-oriented coping into subscales of distraction and social diversion coping. The internal consistency reliability (Cronbach's $\alpha$ ) of the original CISS was $0.78-0.87$ for task-oriented coping, 
$0.78-0.87$ for emotion-oriented coping, and $0.70-0.80$ for avoidance-oriented coping.

\section{Eysenck Personality Questionnaire Revised Short Scale for Chinese (EPQ-RSC)}

The EPQ-RSC comprises four subscales assessing extroversion, neuroticism, psychoticism, and lying. Each subscale comprises 12 items, for a total of 48 . The questionnaire has good reliability and validity and has been qualified by the psychological measurement committee in China. ${ }^{19}$

\section{Emotion scales}

The Beck Anxiety Inventory (BAI) was adopted to evaluate participants' anxiety. The Chinese version of the BAI has good reliability and validity. ${ }^{14}$ The BAI has 21 items, each of which is rated on a four-point scale of severity, which ranged from 1 (none) to 4 (severe). In the data analysis, we used the standardized score; this meant that we summed the 21-item scores to obtain the raw total scores, which were then entered into the formula "int $(1.19 \times \mathrm{X})$ " to achieve a standardized score. In general, a BAI score of $>45$ indicates clinical anxiety.

The Beck Depression Inventory (BDI) was used to evaluate participants' depression. The Chinese version of the BDI has good reliability and validity. ${ }^{20}$ It comprises 21 items representing a symptom of depression, each of which is rated on a four-point scale (ranging from 0 to 3 ) according to its severity. For the data analysis, we summed the 21 items to obtain a total score that ranges from 0 to 63 . Higher scores indicate more severe depression, with scores of 10-19 indicating mild depression, 0-29 moderate depression, and 30-51 severe depression.

The Positive and Negative Affect Scale (PANAS) comprises 20 items that measure one of two emotion dimensions: positive affect (10 items) and negative affect (10 items). Participants made decisions according to their present states. The items are rated on a five-point Likert ranging from 1 ("nothing") to 5 ("very much"). In the data analysis, we summed the scores of all 10 items in the PANAS to arrive at positive and negative affect scores, respectively. The positive and negative affect scores range from 10 to 50. The Chinese version of the PANAS has good reliability and validity, making it a valid tool for evaluating individual emotion. ${ }^{21}$

\section{Procedure}

The participants completed the CISS-SFC along with the EPQ-RSC, BAI, BDI, and PANAS. Participants completed the scales in class and got class work score, and for those who did not want to complete the scales, they had to hand in the class work in other forms. Our procedure was approved by the ethics committee of the School of Psychology of Beijing Normal University. Throughout the whole data collection process, the participants could quit at any time.

\section{Data analysis}

LISREL8.8 was used to perform the confirmatory factor analysis, while SPSS Statistics 16.0 was used for the correlation analysis.

\section{Results}

\section{Item analysis}

First, we conducted a correlation analysis of the scores of each item and the summed scores of the subscales they comprised (task-oriented, emotion-oriented, distraction, and social diversion copings). The results showed that the item-total correlations for the task-oriented subscale were between 0.64 and 0.73 ; for the emotion-oriented subscale were between 0.31 and 0.73 ; for the distraction subscale were between 0.48 and 0.81 ; and for the social diversion subscale were between 0.75 and 0.80 , all of these correlations were significant. The results of the correlation analysis are shown in Tables 1-4.

\section{Reliability and validity analysis}

\section{Cronbach's $\alpha$ reliability and test-retest reliability}

The Cronbach's $\alpha$ coefficient of the whole scale was 0.80 . The Cronbach's $\alpha$ coefficients for the task-oriented, emotionoriented, distraction, and social diversion coping subscales were $0.81,0.74,0.70$, and 0.66 , respectively. The retest data after the 2-week interval showed that the test-retest reliability of the task-oriented, emotion-oriented, distraction, and social diversion coping subscales was $0.78,0.74,0.70$, and 0.65 , respectively.

\section{Construct validity}

LISREL8.8 was used to conduct a confirmatory factor analysis of the four-factor model (task-oriented, emotion-oriented,

Table I Item-total correlation coefficients for task-oriented coping $(\mathrm{N}=972)$

\begin{tabular}{lll}
\hline Item & $\boldsymbol{r}$ & $\boldsymbol{P}$-value \\
\hline A2 & 0.69 & $<0.00 \mathrm{I}$ \\
$\mathrm{A} 6$ & 0.71 & $<0.00 \mathrm{I}$ \\
$\mathrm{A} 8$ & 0.67 & $<0.00 \mathrm{I}$ \\
$\mathrm{AlI}$ & 0.73 & $<0.00 \mathrm{I}$ \\
$\mathrm{Al3}$ & 0.64 & $<0.00 \mathrm{I}$ \\
$\mathrm{Al6}$ & 0.73 & $<0.00 \mathrm{I}$ \\
Al9 & 0.64 & $<0.00 \mathrm{I}$ \\
\hline
\end{tabular}


Table 2 Item-total correlation coefficients for emotion-oriented coping $(N=972)$

\begin{tabular}{lll}
\hline Item & $\boldsymbol{r}$ & $\boldsymbol{P}$-value \\
\hline $\mathrm{A} 3$ & 0.69 & $<0.00 \mathrm{I}$ \\
$\mathrm{A} 5$ & 0.71 & $<0.00 \mathrm{I}$ \\
$\mathrm{A} 10$ & 0.74 & $<0.00 \mathrm{I}$ \\
$\mathrm{A} 12$ & 0.67 & $<0.00 \mathrm{I}$ \\
$\mathrm{AI4}$ & 0.73 & $<0.00 \mathrm{I}$ \\
$\mathrm{AI7}$ & 0.53 & $<0.00 \mathrm{I}$ \\
$\mathrm{A} 20$ & $0.3 \mathrm{I}$ & $<0.00 \mathrm{I}$ \\
\hline
\end{tabular}

distraction, and social diversion copings) of the CISS-SFC (item 20 was removed). The results showed that the goodness-of-fit index (GFI) for the model was 0.930, while the comparative fit index (CFI) was 0.930 , the incremental fit index (IFI) was 0.930 , the $\chi^{2} / d f$ was 4.645 , the root mean residual (RMR) was 0.070 , and the root mean square error of approximation (RMSEA) was 0.062 (Table 5). The results of the confirmatory factor analysis for the four-factor model are shown in Figure 1.

\section{Criterion-related validity}

Correlation analysis of stress coping and personality traits and emotion

We used the EPQ-RSC as a criterion variable to examine the criterion validity of the CISS-SFC. The results showed that the task-oriented coping subscale of the CISS-SFC was negatively correlated with the neuroticism subscale of the EPQ-RSC and positively correlated with the extraversion subscale. By contrast, the emotion-oriented coping subscale of CISS-SFC was positively correlated with the neuroticism subscale and negatively correlated with the extraversion subscale. The distraction coping subscale was positively correlated with the neuroticism and extraversion subscales and negatively correlated with the psychoticism subscale of the EPQ-RSC. Finally, the social diversion coping subscale was positively correlated with the extraversion subscale of the EPQ-RSC and negatively correlated with the psychoticism subscale. The coefficients are shown in Table 6.

The Chinese versions of the BAI, BDI, and PANAS were also used as criterion variables to examine the criterion

Table 3 Item-total correlation coefficients for distraction coping $(N=972)$

\begin{tabular}{lll}
\hline Item & $\boldsymbol{r}$ & $\boldsymbol{P}$-value \\
\hline AI & 0.48 & $<0.00 \mathrm{I}$ \\
A4 & 0.81 & $<0.00 \mathrm{I}$ \\
A9 & 0.78 & $<0.00 \mathrm{I}$ \\
Al8 & 0.80 & $<0.00 \mathrm{I}$ \\
\hline
\end{tabular}

Table 4 Item-total correlation coefficients for social diversion coping $(N=972)$

\begin{tabular}{lll}
\hline Item & $\boldsymbol{r}$ & $\boldsymbol{P}$-value \\
\hline A7 & 0.77 & $<0.001$ \\
AI5 & 0.75 & $<0.001$ \\
A2I & 0.80 & $<0.001$ \\
\hline
\end{tabular}

validity of the CISS-SFC. The results showed that the taskoriented coping subscale of the CISS-SFC was positively correlated with positive affect, while the emotion-oriented coping subscale was positively correlated with anxiety and negative affect. The distraction coping subscale was positively correlated with anxiety, positive affect, and negative affect, and the social diversion coping subscale was positively correlated with positive affect. The coefficients are shown in Table 7.

\section{Discussion}

This study aimed to explore the psychometric properties of Chinese version of CISS-21 (CISS-SFC) in a university sample. Scale correlation coefficients between CISS-SFC and other variables were also obtained. The results of a confirmatory factor analysis showed that the CISS-SFC has a four-factor model (task-oriented, emotion-oriented, distraction, and social diversion copings), which are consistent with results from previous studies..$^{18}$ Coping was found to be related to emotional characteristics, mood, and personality traits of the individual in two studies..$^{22,23}$

In our study, the CISS-SFC had clear correlations with various emotion and personality instruments. Specifically, task-oriented coping was positively correlated with extroversion and positive affect and negatively correlated with neuroticism. Emotion-oriented coping was positively correlated with neuroticism, anxiety, and negative affect and negatively correlated with extraversion. Distraction coping was positively correlated with neuroticism, extraversion, anxiety, positive affect, and negative affect and negatively correlated with psychoticism. Finally, social diversion coping was positively correlated with extraversion and positive affect and negatively correlated with psychoticism.

As noted before, task-oriented coping was positively correlated with positive affect and emotion-oriented coping was positively correlated with negative affect. These results accorded with those of Boysan, ${ }^{17}$ who found that, in a Turkish sample, positive affect was related to the task-oriented coping ( $r=0.36)$ and negative affect was related to emotionoriented coping $(r=0.44)$. However, there were several differences between our study and Boysan's. Because we 
Table 5 Fit indexes and error terms of the confirmatory factor analysis for the CISS-SFC $(N=972)$

\begin{tabular}{llllllllll}
\hline Model & $\chi^{2}$ & df & $\chi^{2} / \mathbf{d f}$ & GFI & NFI & CFI & IFI & RMR & RMSEA \\
\hline Four factors & 761.72 & 164 & 4.645 & 0.930 & 0.910 & 0.930 & 0.930 & 0.070 & 0.062 \\
\hline
\end{tabular}

Abbreviations: CISS-SFC, Coping Inventory for Stressful Situations - Short Form for Chinese; GFI, goodness-of-fit index; NFI, normed fit index; CFI, comparative fit index; IFI, incremental fit index; RMR, root mean residual; RMSEA, root mean square error of approximation.

tested the four-factor model of the CISS-21, we further found correlations between distraction coping, social diversion coping, and emotion. In particular, distraction coping was positively correlated with positive and negative affect and social diversion coping was positively correlated with positive affect. These correlation results further showed that task-oriented, emotion-oriented, and social diversion coping styles were sensitive to specific emotions, while distraction coping was relatively insensitive to detection of specific types of emotion.

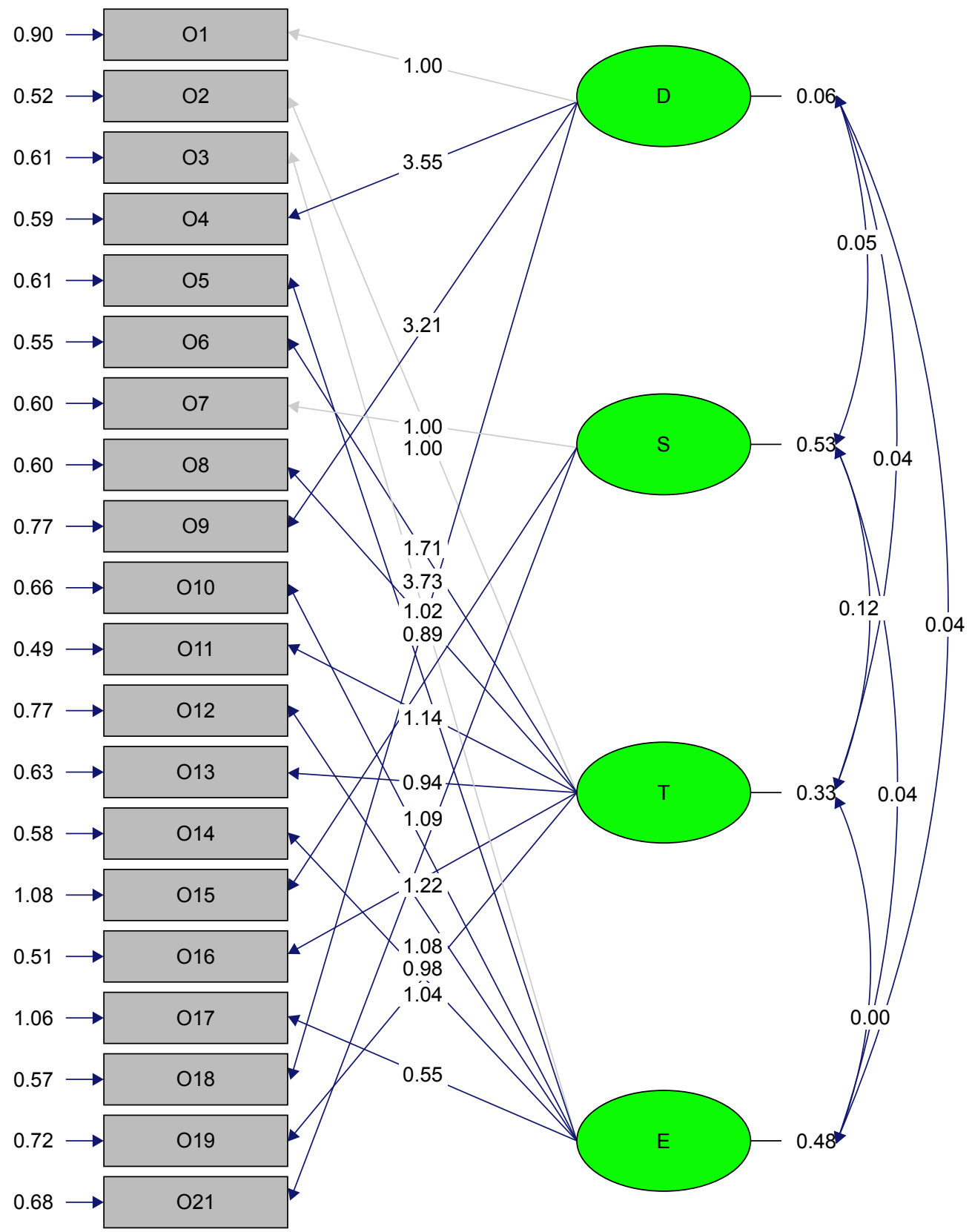

Figure I Result map of the confirmatory factor analysis for the four-factor model.

Abbreviations: D, distraction coping; S, social-diversion coping; T, task-oriented coping; E, emotion-coping. 
Table 6 Correlation coefficients of the CISS-SFC and EPQ-RSC $(N=972)$

\begin{tabular}{llll}
\hline & Neuroticism & Psychoticism & Extraversion \\
\hline Task-oriented coping & $-0.107^{* *}$ & 0.036 & $0.229 * * *$ \\
Emotion-oriented coping & $0.474^{* * *}$ & -0.043 & $-0.117^{* * *}$ \\
Distraction coping & $0.079^{*}$ & $-0.073^{*}$ & $0.099^{* *}$ \\
Social diversion coping & -0.039 & $-0.083^{* *}$ & $0.273^{* * *}$ \\
\hline
\end{tabular}

Notes: Task-oriented, emotion-oriented, distraction, and social diversion coping are the four dimensions of the CISS-SFC. Neuroticism, psychoticism, and extraversion are the three subscales of the EPQ-RSC. $* P<0.05 ; * * P<0.01$; $* * * P<0.001$. Abbreviations: CISS-SFC, Coping Inventory for Stressful Situations - Short Form for Chinese; EPQ-RSC, Eysenck Personality Questionnaire Revised Short Scale for Chinese.

Additionally, unlike the original CISS-SFC, ${ }^{18}$ we did not find any relation between anxiety, depression, and task- and emotion-oriented copings. Cohan et al used the CISS short form and found that depression and anxiety were negatively correlated with task-oriented coping and positively correlated with emotion-oriented coping in a university student sample. In contrast, in this study, we observed only a positive correlation between emotion-oriented coping and anxiety, which means that emotion-oriented coping may have cross-cultural consistency; this is relevant to research on the relations between coping and anxiety, as it would help in properly evaluating university students' anxiety.

In the CISS-SFC, the task-oriented and emotion-oriented coping factors were found to be orthogonal and well explained by their seven items. Furthermore, avoidanceoriented coping was divided into two subscales, each of which had three items. These two subscales described specific avoidance behavior (ie, distraction and social diversion) rather than the overall avoidance reaction. In the Chinese sample, anxiety was positively correlated with emotionoriented and distraction copings; positive affect was positively correlated with task-oriented, distraction, and social diversion copings; and negative affect was positively correlated with emotion-oriented and social diversion copings.

Table 7 Correlation coefficients of the CISS-SFC and emotion scales (BAI, BDI, and PANAS, $N=972$ )

\begin{tabular}{lllll}
\hline & Anxiety & Depression & $\begin{array}{l}\text { Positive } \\
\text { affect }\end{array}$ & $\begin{array}{l}\text { Negative } \\
\text { affect }\end{array}$ \\
\hline Task-oriented coping & -0.037 & -0.025 & $0.324 * * *$ & -0.053 \\
Emotion-oriented coping & $0.328 * * *$ & 0.012 & -0.049 & $0.362^{* * *}$ \\
Distraction coping & $0.083^{*}$ & 0.041 & $0.154 * * *$ & $0.076 *$ \\
Social diversion coping & 0.019 & 0.057 & $0.168^{* * * *}$ & -0.031 \\
\hline
\end{tabular}

Notes: Task-oriented, emotion-oriented, distraction, and social diversion coping are the four dimensions of the CISS-SFC. $* P<0.05$; $* * * P<0.001$.

Abbreviations: CISS-SFC, Coping Inventory for Stressful Situations - Short Form for Chinese; BAI, Beck Anxiety Inventory; BDI, Beck Depression Inventory; PANAS, Positive and Negative Affect Scale.
The correlations between the CISS-SFC and the EPQ-RSC showed that task-oriented coping was negatively correlated with neuroticism and positively correlated with extraversion; emotion-oriented coping was positively correlated with neuroticism and negatively correlated with extraction; distraction coping was positively correlated with neuroticism and extraversion and negatively correlated with psychoticism; and social diversion coping was positively correlated with extraversion and negatively correlated with neuroticism and psychoticism. Thus, this demonstrated that task-oriented, emotion-oriented, distraction, and social diversion coping subscales were useful tools for evaluating individuals' stress coping style.

This study had some limitations. Although our data were taken from a large sample, the sample mainly comprised healthy adult university students. In the future, we must collect data from other participants, especially those with clinical symptoms and disorders, to fully estimate the clinical application of the CISS-SFC. Moreover, to evaluate the stability of the tool, we tested the scale 2 weeks later. It would nevertheless be necessary to retest the scale over a longer interval to ensure its reliability.

\section{Conclusion}

Overall, a confirmatory factor analysis indicated that the original four-factor model of the CISS-21 fit well to a Chinese sample. Thus, the Chinese version of this scale is satisfactorily valid and reliable in Chinese.

\section{Acknowledgments}

The work was funded by the Fundamental Research Funds for the Central Universities. The authors would like to express their gratitude for the support of these projects.

\section{Author contributions}

All authors contributed toward data analysis, drafting and critically revising the paper and agree to be accountable for all aspects of the work.

\section{Disclosure}

The authors report no conflicts of interest in this work.

\section{References}

1. Lyon BL. Psychological stress and coping: framework for poststroke psychosocial care. Top Stroke Rehabil. 2002;9(1):1-15.

2. Keil RM. Coping and stress: a conceptual analysis. J Adv Nurs. 2004; 45(6):659-665

3. Khosla M. Positive affect and coping with stress. J Indian Acad Appl Psychol. 2006;32(3):185-192.

4. Lazarus RS, Folkman S. Stress, Appraisal, and Coping. New York: Springer; 1984:141. 
5. Skinner EA, Edge K, Altman J, Sherwood H. Searching for the structure of coping: a review and critique of category systems for classifying ways of coping. Psychol Bull. 2003;129(2):216-219.

6. Somerfield MR, McCrae RR. Stress and coping research: methodological challenges, theoretical advances, and clinical applications. Am Psychol. 2000;55(6):620-625.

7. Endler NS, Parker JDA. The multidimensional assessment of coping: a critical evaluation. J Pers Soc Psychol. 1990;58(5):844-854.

8. Endler NS, Parker JDA. Assessment of multidimensional coping: task, emotional, and avoidance strategies. Psychol Assess. 1994;6:50-60.

9. Cosway R, Endler NS, Sadler AJ, Deary IJ. The coping inventory for stressful situations: factorial structure and associations with personality traits and psychological health. J Appl Biobehav Res. 2000;5(2): 121-143.

10. Rafnsson FD, Smari J, Windle M, Mears SA, Endler NS. Factor structure and psychometric characteristics of the Icelandic version of the coping inventory for stressful situations (CISS). Pers Individ Dif. 2006;40:1247-1258

11. Brands IMH, Kohler S, Stapert SZ, Wade DT, van Heugten CM. Psychometric properties of the coping inventory for stressful situations (CISS) in patients with acquired brain injury. Psychol Assess. 2014;26(3): 848-856.

12. Endler NS, Parker JDA. Coping Inventory for Stressful Situations (CISS): Manual. Second ed. Toronto: Multi-Health Systems; 1999.

13. Christensen MV, Kessing LV. Clinical use of coping in affective disorder, a critical review of the literature. Clin Pract Epidemiol Ment Health. 2005;1(1):20.

14. McWilliams LA, Cox BJ, Ennus MW. Use of the coping inventory for stressful situations in a clinically depressed sample: factor structure, personality correlates, and prediction of distress. J Clin Psychol. 2003; 59(4):1371-1385.
15. Shewchuk RM, Elliott TR, MacNair-Semands RR, Harkins S. Trait influences on stress appraisal and coping: an evaluation of alternative frameworks. J Appl Soc Psychol. 1999;29:685-704.

16. Uehara T, Sakado K, Sakado M, Sato T, Someya T. Relationship between stress coping and personality in patients with major depressive disorder. Psychother Psychosom. 1999;68(1):26-30.

17. Boysan M. Validity of the coping inventory for stressful situations short form (CISS-21) in a non-clinical Turkish sample. J Psychiatry Neurol Sci. 2012;25:101-107.

18. Cohan SL, Jang KL, Stein MB. Confirmatory factor analysis of a short form of the coping inventory for stressful situations. J Clin Psychol. 2006;62(3):273-283.

19. Qian MY, Wu GC, Zhu RQ, Zhang P. Development of the revised Eysenck personality questionnaire short scale for Chinese (EPQ-RSC). Acta Psychol Sin. 2000;32(3):317-323.

20. Wang XD, Wang XL, Ma H. Rating scales for mental health. Chin J Ment Health. Beijing, China: Mental Health in Chinese Press; 1999: 191-194.

21. Huang L, Yang T, Ji Z. Applicability of the positive and negative affect scale in Chinese. Chin Ment Health J. 2003;17:54-56.

22. Lue B, Chen H, Wang C, Cheng Y, Chen MC. Stress, personal characteristics and burnout among first postgraduate year residents: a nationwide study in Taiwan. Med Tech. 2010;32(5):400-407.

23. Austin EJ, Saklofske DH, Mastora SM. Emotional intelligence, coping and exam-related stress in Canadian undergraduate students. Aust $J$ Psychol. 2010;62:42-50.
Neuropsychiatric Disease and Treatment

\section{Publish your work in this journal}

Neuropsychiatric Disease and Treatment is an international, peerreviewed journal of clinical therapeutics and pharmacology focusing on concise rapid reporting of clinical or pre-clinical studies on a range of neuropsychiatric and neurological disorders. This journal is indexed on PubMed Central, the 'PsycINFO' database and CAS,

\section{Dovepress}

and is the official journal of The International Neuropsychiatric Association (INA). The manuscript management system is completely online and includes a very quick and fair peer-review system, which is all easy to use. Visit http://www.dovepress.com/testimonials.php to read real quotes from published authors. 